\title{
Spatial patterns and environmental factors influencing leaf carbon content in the forests and shrublands of China
}

\author{
ZHAO Hang ${ }^{1,2}, X \mathrm{Li}^{1,2}$, WANG Qiufeng ${ }^{1,2}$, TIAN Jing ${ }^{1,2}$, TANG Xuli ${ }^{3}$, TANG Zhiyao ${ }^{4}$, \\ XIE Zongqiang ${ }^{5}$, HE Nianpeng ${ }^{1,2}$, 'YU Guirui ${ }^{1,2}$ \\ 1. Key Laboratory of Ecosystem Network Observation and Modeling, Institute of Geographic Sciences and \\ Natural Resources Research, CAS, Beijing 100101, China; \\ 2. University of Chinese Academy of Sciences, Beijing 100049, China; \\ 3. South China Botanical Garden, CAS, Guangzhou 510650, China; \\ 4. Department of Ecology, College of Urban and Environmental Sciences, Peking University, Beijing 100871, China; \\ 5. State Key Laboratory of Vegetation and Environmental Change, Institute of Botany, CAS, Beijing 100093, China
}

\begin{abstract}
Leaf carbon content (LCC) is widely used as an important parameter in estimating ecosystem carbon (C) storage, as well as for investigating the adaptation strategies of vegetation to their environment at a large scale. In this study, we used a dataset collected from forests (5119 plots) and shrublands (2564 plots) in China, 2011-2015. The plots were sampled following a consistent protocol, and we used the data to explore the spatial patterns of LCC at three scales: plot scale, eco-region scale $(n=24)$, and eco-region scale $(n=8)$. The average LCC of forests and shrublands combined was $45.3 \%$, with the LCC of forests (45.5\%) being slightly higher than that of shrublands (44.9\%). Forest LCC ranged from $40.2 \%$ to $51.2 \%$ throughout the 24 eco-regions, while that of shrublands ranged from $35 \%$ to $50.1 \%$. Forest LCC decreased with increasing latitude and longitude, whereas shrubland LCC decreased with increasing latitude, but increased with increasing longitude. The LCC increased, to some extent, with increasing temperature and precipitation. These results demonstrate the spatial patterns of LCC in the forests and shrublands at different scales based on field-measured data, providing a reference (or standard) for estimating carbon storage in vegetation at a regional scale.
\end{abstract}

Keywords: carbon storage; eco-regions; foliar carbon; shrubs; stoichiometry; China

\section{Introduction}

Leaves are a plant's main interface with the environment for photosynthesis and transpiration. Therefore, leaves have a large influence on the carbon (C) and water cycle (Chapin et

Received: 2017-05-31 Accepted: 2017-10-17

Foundation: National Key R\&D Program of China, No.2016YFA0600103, No.2017YFA0604803; Youth Innovation Research Team Project, No.LENOM2016Q0005

Author: Zhao Hang (1991-), PhD, specialized in plant carbon and nitrogen storage. E-mail: zhh1108@163.com

"Corresponding author: Yu Guirui, Professor, E-mail: yugr@igsnrr.ac.cn 
al., 2002; Ehleringer and Field, 1993). To some extent, leaf carbon content (LCC) reflects the adaption strategies of plants to their environment at a large scale (Wang and $\mathrm{Yu}, 2008$ ). Furthermore, the leaf is an important organ that stores $\mathrm{C}$ in plants. To estimate vegetation $\mathrm{C}$ storage in terrestrial ecosystems accurately, it is necessary to measure LCC.

Many studies have explored regional variation in LCC with different research aims. Overall, the $\mathrm{C}$ content of different plant organs (e.g., leaves, stems, and roots) differs significantly, and tends to exceed 50\% (Bert and Danjon, 2006; Tolunay, 2009). Moreover, LCC noticeably varies among different plant species or plant functional groups (Jagodzinski, et al., 2012; Yerena-Yamallel et al., 2011). Han et al. (2009) reported an average LCC of $45.1 \%$ for 358 plants in Beijing, China. Yu et al. (2012) reported an average LCC of $44.5 \%$ $(41.6 \%-47 \%)$ for northeast China's forests. Furthermore, Ma et al. (2002) found an average LCC of $49.4 \%$ for 10 shrub species in north China, and an average LCC of $50 \%$ for eight dominant tree species. Cheng et al. (2008) obtained an average LCC of $43 \%$ for 14 shrub species from Mt. Xiaolongshan in Gansu Province, China. Overall, these results indicate that LCC varies widely across regions and between trees and shrubs. Unfortunately, only a few studies have addressed this problem at different spatial scales, leaving a gap in our knowledge on how exactly LCC varies with the environment.

Understanding how LCC varies spatially and across vegetation types would facilitate better estimates of $\mathrm{C}$ storage in leaves, which is an important component of terrestrial ecosystems. In general, two approaches can estimate $\mathrm{C}$ storage in ecosystems by using LCC. The first approach involves conducting direct measurements of LCC, while the second uses an empirical average as a substitute. Many estimates of leaf $\mathrm{C}$ storage at the regional scale have used an LCC of $45 \%$ or $50 \%$ when employing the substitution method (Fang et al., 2001; Houghton et al., 2000; Liu et al., 2000; Navar, 2009; Sykes and Prentice, 1996; Wang et al., 2001; Zhou et al., 2000). However, LCC is influenced by vegetation type, climate, topography, and other factors. Therefore, although the substitution method is simple and economic, high uncertainty due to the spatial variation in LCC is unavoidable. Other studies have measured the LCC of specific plant species or regions directly (Birdsey, 1992; Cheng et al., 2008; Du et al., 2009; Ren et al., 2012; Shvidenko et al., 1996; Turner et al., 1995; Yang et al., 2014; Zhao et al., 2014). However, direct measurements are very costly and time-consuming, especially at large scales. Therefore, it is necessary to improve our understanding on the spatial variation of LCC to update estimates of global C storage.

Overall, there is a need to explore the large-scale spatial variation of LCC, and to develop a series of more accurate standards for LCC at different regional scales. In this study, we compiled the LCC data of 7683 Chinese sampling plots from forests and shrublands. We subsequently analyzed the statistical characteristics, spatial patterns, and correlations of these two vegetation types with temperature and precipitation at three different scales (plot [7683 plots], eco-region [24 groupings], and larger eco-region [8 groupings]). All data were derived from the Ecosystem Carbon Sequestration Project of the Chinese Academy of Sciences (XDA05050000). The main objectives of this study were to: 1) analyze the statistical characteristics and spatial distribution of LCC in the forests and shrublands of China; 2) explore regional differences in LCC at different scales; and 3) develop a series of accurate LCC standards at different scales for future studies. 


\section{Data and methods}

\subsection{Data source}

All of the LCC data from the 7683 plots (5119 forest plots and 2564 shrubland plots) originated from the Ecosystem Carbon Sequestration Project (2011-2015), which was part of the strategic priority research program "Climate Change: Carbon Budget and Related Issues" of the Chinese Academy of Sciences (XDA05050000). The meteorological data were obtained from the National Data Sharing Infrastructure of Earth System Science (http://www.geodata.cn/).

Before measuring the $\mathrm{C}$ content of different components of the terrestrial ecosystems (e.g., leaf, stem, root, and soil), we developed a protocol to make the operational procedures consistent with the various (regional) investigators. This protocol included instructions on how to set up the sampling plots, how to collect and store the samples, and how to conduct the chemical analyses (Xie et al., 2015; Zhou et al., 2015). In brief, we set up the plots using meshed and normalized sampling, based on the spatial distribution of the forests and shrublands at regional, site, and plot scales in China. This practice ensured that all plots used in our study were representative. For example, the forests in China were first divided into six main types or regions, based on the forest type, climate, and geographical and administrative areas. We subsequently meshed each type into different forests with a more complex and higher resolution (or higher mesh density). Study sites were selected from these meshes at a sampling standard of $3 \%-5 \%$. At each selected site, we set up three $10 \mathrm{~m} \times 10 \mathrm{~m}$ plots to conduct the field measurements and sampling. A similar procedure was used to select the shrubland study plots in China, even though plot size was different $(5 \mathrm{~m} \times 5 \mathrm{~m})$. In total, there were 7683 plots, including 5119 forest plots and 2564 shrubland plots. The spatial distribution of these plots is shown in Figure 1.

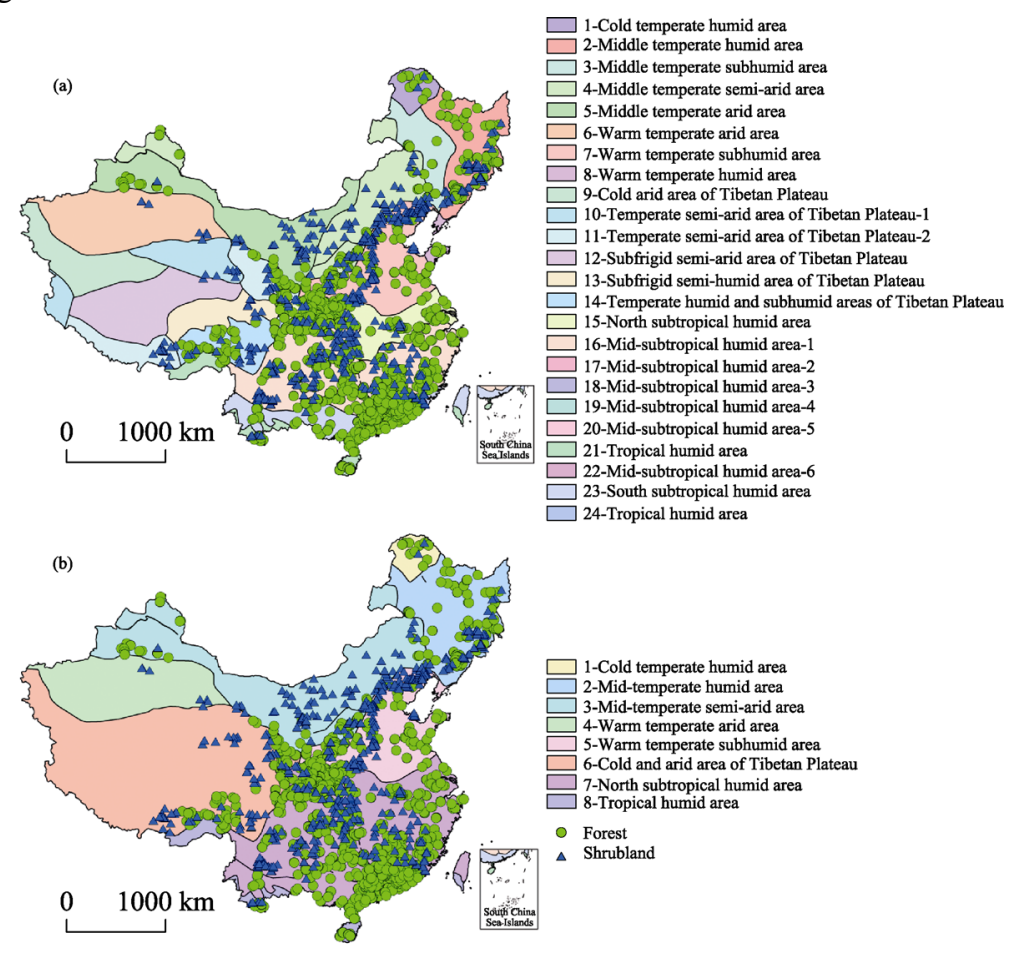

Figure 1 Sampling sites of forests and shrublands in China divided into 24 eco-regions (a) and 8 eco-regions (b) 
In each plot, we collected a mixed leaf sample (about $300 \mathrm{~g}$ fresh weight), which contained more than five dominant plant species. The dominant tree and shrub species were determined based on their overall basal area at the site. Subsequently, forest LCC was measured using the wet combustion method (potassium dichromate-sulfuric acid oxidation process) (Fu and Sun, 2013). Shrub LCC was measured using the dry combustion method (PE-2400 II, USA).

\subsection{Analysis and statistics}

We first obtained the distribution and statistical properties of the data through a descriptive analysis. All data were subsequently classified into different eco-regions. For this process, we adopted the regional classification of $\mathrm{Fu}$ et al. (2001), who separated the terrestrial ecosystems of China into 24 eco-regions, and eight larger eco-regions. Regression analyses were performed to explore the relationships between LCC and their corresponding longitude and latitude, in addition to the relationships of LCC with environmental variables (mean annual temperature [MAT] and mean annual precipitation [MAP]). These regression analyses were conducted at a plot scale, the eco-region scale, and the larger eco-region scale. Furthermore, a one-way analysis of variance (ANOVA) was performed to identify differences in LCC among different regions, with a post-hoc LSD test.

All maps were made in Arcgis 10.2, the graphs in Sigmaplot 12.5, and the statistical analyses in SPSS 19. For the statistical analyses, the significance level was set at $\alpha=0.05$.

\section{Results}

\subsection{Changes in forest and shrubland LCC at different scales}

\subsubsection{Plot scale}

LCC ranged from $27.62 \%$ to $62.67 \%$ for the forests and shrublands of China, with a mean of $45.30 \%$ (Figure 2), and this range showed a normal distribution. Mean forest LCC was $45.51 \%$, while that of shrublands was $44.91 \%$. LCC was, to some extent, higher in forests than in shrublands.

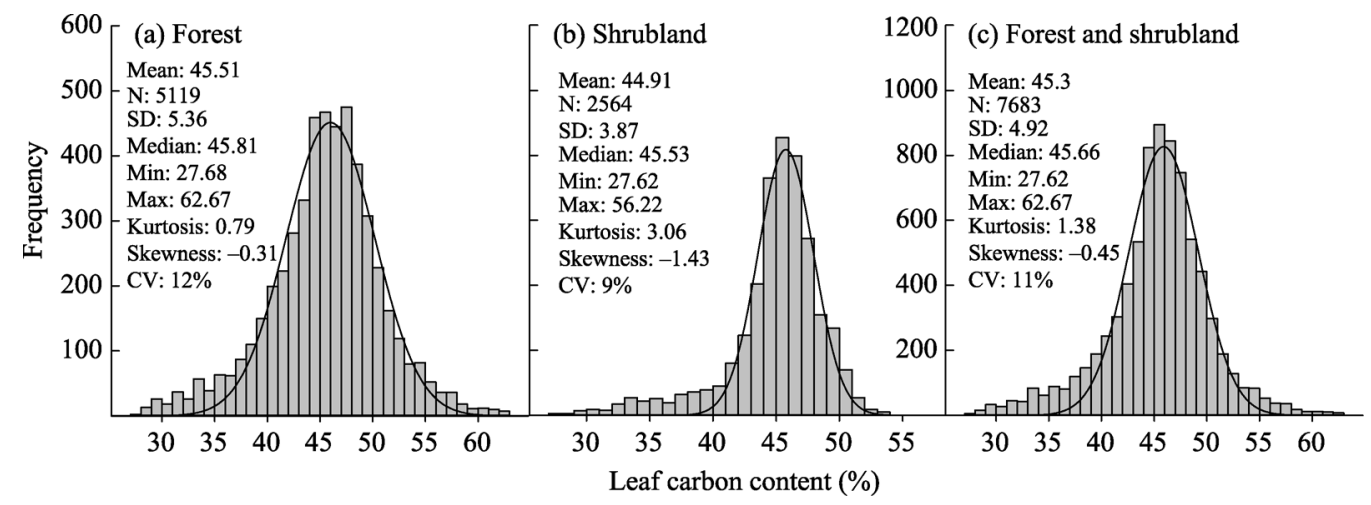

Figure 2 Frequency distribution of leaf carbon content (LCC, \%) in the forests and shrublands of China (N, sample number; SD, standard deviation; Min, minimum value; Max, maximum value; CV, coefficient of variation)

\subsubsection{Eco-region scale}

At the scale of the 24 eco-regions, forest LCC was the highest in the mid-subtropical humid 
area-5 (51.24\%), and the lowest in the mid-temperate humid region $(40.18 \%)$, with some regions differing significantly from one another (Table 1). Shrubland LCC also significantly differed among the various regions, being the highest in the tropical humid area $(50.12 \%)$ and the lowest in the temperate semi-arid area of the Tibetan Plateau (34.99\%).

Table 1 Changes in leaf carbon content (LCC, \%) of forests and shrublands in the 24 eco-regions of China

\begin{tabular}{|c|c|c|c|c|c|c|c|c|c|}
\hline \multirow{2}{*}{ Region } & \multicolumn{3}{|c|}{ LCC of forests } & \multicolumn{3}{|c|}{ LCC of shrublands } & \multicolumn{3}{|c|}{ LCC of forests and shrublands } \\
\hline & Mean $(\%)$ & $\mathrm{N}^{*}$ & SD & Mean $(\%)$ & $\mathrm{N}$ & SD & Mean $(\%)$ & $\mathrm{N}$ & SD \\
\hline $1^{\dagger}$ & $42.73^{\mathrm{Ag} \S}$ & 29 & 7.44 & $46.10^{\text {Abcde }}$ & 6 & 3.18 & $43.31^{\mathrm{g}}$ & 35 & 6.98 \\
\hline 2 & $40.18^{\mathrm{Ah}}$ & 541 & 6.96 & $44.13^{\mathrm{Be}}$ & 299 & 2.35 & $41.59^{\mathrm{h}}$ & 840 & 6.06 \\
\hline 3 & $41.56^{\mathrm{Ag}}$ & 51 & 5.95 & $45.8^{\mathrm{Bbcd}}$ & 19 & 1.29 & $42.71^{\mathrm{g}}$ & 70 & 5.45 \\
\hline 4 & $46.84^{\text {Ade }}$ & 197 & 4.85 & $45.19^{\mathrm{Bcd}}$ & 245 & 2.32 & $45.93^{\mathrm{d}}$ & 442 & 3.76 \\
\hline 5 & $45.71^{\text {Aef }}$ & 44 & 4.38 & $39.84^{\mathrm{Bf}}$ & 230 & 5.34 & $40.78^{\mathrm{i}}$ & 274 & 5.62 \\
\hline 6 & - & - & - & $36.96^{\mathrm{g}}$ & 24 & 3.87 & $36.96^{\mathrm{j}}$ & 24 & 3.87 \\
\hline 7 & $45.17^{\mathrm{Af}}$ & 645 & 4.54 & $45.47^{\mathrm{Ac}}$ & 458 & 2.00 & $45.30^{\mathrm{ef}}$ & 1103 & 3.70 \\
\hline 8 & $49.18^{\text {bcd }}$ & 27 & 2.22 & - & - & - & $49.18^{\mathrm{ab}}$ & 27 & 2.22 \\
\hline 9 & - & - & - & - & - & - & - & - & - \\
\hline 10 & - & - & - & $34.99^{\mathrm{h}}$ & 54 & 4.38 & $34.99^{j}$ & 54 & 4.38 \\
\hline 11 & $49.02^{\mathrm{Abc}}$ & 45 & 4.03 & $46.14^{\mathrm{Bb}}$ & 148 & 4.08 & $46.81^{\mathrm{cd}}$ & 193 & 4.24 \\
\hline 12 & - & - & & $43.85^{\mathrm{e}}$ & 3 & 0.71 & $43.85^{\text {fghi }}$ & 3 & 0.71 \\
\hline 13 & - & - & - & $45.77^{\mathrm{bc}}$ & 64 & 3.15 & $45.77^{\mathrm{def}}$ & 64 & 3.15 \\
\hline 14 & $48.21^{\mathrm{Ac}}$ & 266 & 3.73 & $48.06^{\mathrm{Aa}}$ & 81 & 3.15 & $48.17^{\mathrm{b}}$ & 347 & 3.60 \\
\hline 15 & $45.52^{\text {Aef }}$ & 651 & 3.46 & $44.78^{\mathrm{Bd}}$ & 118 & 1.96 & $45.41^{\mathrm{e}}$ & 769 & 3.28 \\
\hline 16 & $46.02^{\mathrm{Ae}}$ & 199 & 3.40 & $45.47^{\text {Acd }}$ & 96 & 1.81 & $45.84^{\mathrm{de}}$ & 295 & 2.98 \\
\hline 17 & $42.62^{\mathrm{Ag}}$ & 265 & 5.14 & $45.66^{\mathrm{Bbc}}$ & 157 & 2.68 & $43.75^{\mathrm{g}}$ & 422 & 4.62 \\
\hline 18 & $46.73^{\text {Ade }}$ & 297 & 4.14 & $45.92^{\mathrm{Bbc}}$ & 149 & 2.32 & $46.46^{\mathrm{d}}$ & 446 & 3.65 \\
\hline 19 & $44.79^{\mathrm{Af}}$ & 661 & 4.10 & $47.01^{\mathrm{Bab}}$ & 46 & 2.28 & $44.94^{\mathrm{f}}$ & 707 & 4.05 \\
\hline 20 & $51.24^{\mathrm{Aa}}$ & 76 & 3.44 & $48.03^{\mathrm{Ba}}$ & 257 & 1.92 & $48.77^{\mathrm{b}}$ & 333 & 2.71 \\
\hline 21 & $49.26^{\mathrm{Abc}}$ & 44 & 2.93 & $50.12^{\mathrm{Aa}}$ & 3 & 0.62 & $49.32^{\mathrm{ab}}$ & 47 & 2.84 \\
\hline 22 & $49.69^{\mathrm{Ab}}$ & 342 & 5.78 & $45.52^{\text {Bbcde }}$ & 17 & 1.48 & $49.49^{\mathrm{a}}$ & 359 & 5.72 \\
\hline 23 & $47.38^{\mathrm{Ad}}$ & 478 & 4.58 & $46.48^{\mathrm{Ab}}$ & 40 & 2.85 & $47.31^{\mathrm{c}}$ & 518 & 4.47 \\
\hline 24 & $45.28^{\mathrm{Aef}}$ & 261 & 4.36 & $44.67^{\text {Ade }}$ & 50 & 1.85 & $45.18^{\mathrm{ef}}$ & 311 & 4.07 \\
\hline
\end{tabular}

${ }^{\dagger}$ Eco-region number corresponding with Figure 1a

${ }^{\ddagger} \mathrm{N}=$ number of sampling sites; $\mathrm{SD}=$ standard deviation

${ }^{\S}$ Different uppercase letters indicate significant differences between forests and shrublands within specific rows at $P$ $<0.05$; Different lowercase letters indicate significant differences among the 24 eco-regions within each column at $P<0.05$

\subsubsection{Larger eco-region scale}

At the scale of the eight eco-regions, forest LCC was the lowest in the mid-temperate humid area $(40.30 \%)$, and the highest in the cold and arid area of the Tibetan Plateau $(48.32 \%)$ (Table 2). Shrubland LCC was the lowest in the warm temperate arid area (36.96\%), and the highest in the tropical humid area $(46.70 \%)$.

\subsection{Spatial patterns of LCC}

Forest LCC exhibited a significant spatial pattern with longitude and latitude $(P<0.001)$. 
Table 2 Leaf carbon content (LCC, \%) of forests and shrublands in the eight larger eco-regions of China

\begin{tabular}{|c|c|c|c|c|c|c|c|c|c|}
\hline \multirow{2}{*}{ Area } & \multicolumn{3}{|c|}{ LCC of forests } & \multicolumn{3}{|c|}{ LCC of shrublands } & \multicolumn{3}{|c|}{ LCC of forests and shrublands } \\
\hline & Mean $(\%)$ & $\mathrm{N}^{*}$ & SD & Mean (\%) & $\mathrm{N}$ & SD & Mean (\%) & $\mathrm{N}$ & SD \\
\hline $1^{\dagger}$ & $42.73^{\mathrm{Ae} \S}$ & 29 & 7.44 & $46.10^{\text {Aabcd }}$ & 6 & 3.18 & $43.31^{\mathrm{d}}$ & 35 & 6.98 \\
\hline 2 & $40.30^{\mathrm{Af}}$ & 592 & 6.89 & $44.23^{\mathrm{Bd}}$ & 318 & 2.33 & $41.67^{\mathrm{e}}$ & 910 & 6.02 \\
\hline 3 & $46.63^{\mathrm{Ab}}$ & 241 & 4.78 & $42.60^{\mathrm{Be}}$ & 475 & 4.87 & $43.96^{\mathrm{d}}$ & 716 & 5.20 \\
\hline 4 & - & - & - & $36.96^{\mathrm{f}}$ & 24 & 3.87 & $36.96^{\mathrm{f}}$ & 24 & 3.87 \\
\hline 5 & $45.33^{\mathrm{Ad}}$ & 672 & 4.53 & $45.47^{\mathrm{Ab}}$ & 458 & 2.00 & $45.39^{\mathrm{c}}$ & 1130 & 3.72 \\
\hline 6 & $48.32^{\mathrm{Aa}}$ & 311 & 3.78 & $44.78^{\mathrm{Bc}}$ & 350 & 5.68 & $46.44^{\mathrm{a}}$ & 661 & 5.19 \\
\hline 7 & $45.95^{\mathrm{Ac}}$ & 2491 & 4.77 & $46.36^{\mathrm{Ba}}$ & 840 & 2.47 & $46.05^{\mathrm{b}}$ & 3331 & 4.31 \\
\hline 8 & $46.65^{\mathrm{Ab}}$ & 743 & 4.61 & $46.70^{\mathrm{Aa}}$ & 133 & 3.18 & $46.66^{\mathrm{a}}$ & 876 & 4.42 \\
\hline
\end{tabular}

Eco-region number corresponding with Figure $1 \mathrm{~b}$

$\mathrm{N}=$ number of sampling sites; $\mathrm{SD}=$ standard deviation

$\S$ Different uppercase letters indicate significant differences between forests and shrublands within specific rows at $P<0.05$; Different lowercase letters indicate significant differences among the 8 larger eco-regions within each column at $P<0.05$.

More specifically, forest LCC decreased with increasing longitude and latitude (Figures 3a and 3d). Furthermore, shrubland LCC was significantly related to latitude $(P<0.001)$ and longitude $(P=0.0057)$. Shrubland LCC decreased with increasing latitude (Figure 3b), but increased with increasing longitude (Figure 3e). For forests and shrublands combined, LCC showed a significant pattern with longitude and latitude $(P<0.001)$, with LCC decreasing with increasing longitude and latitude (Figures $3 \mathrm{c}$ and $3 \mathrm{f}$ ). Furthermore, the LCC regressions with latitude did not differ significantly for forests, shrublands, or the two combined (slope: $P=0.513$, intercept: $P=0.610$ ). In contrast, the LCC regressions with longitude differed significantly for forests, shrublands, and the combined data (slope: $P<0.001$, intercept: $P<0.001$ ).

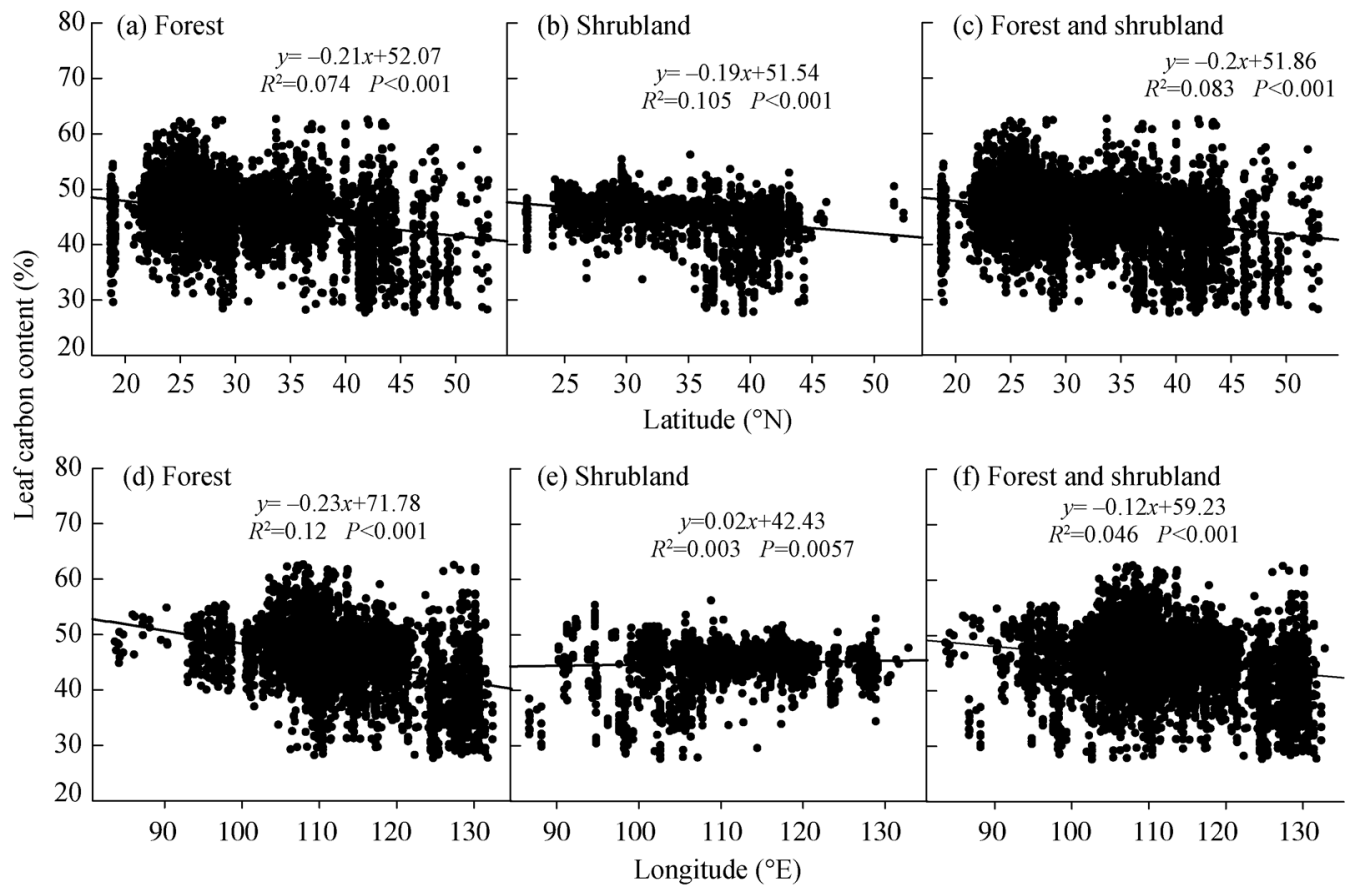

Figure 3 Changes in leaf carbon content (LCC, \%) with latitude and longitude in the forests and shrublands of China at the plot scale 


\subsection{Environmental factors influencing LCC}

\subsubsection{Plot scale}

Forest and shrubland LCC was significantly related to MAT and MAP at the plot scale $(P<$ 0.001). In general, LCC increased gradually with increasing MAT and MAP. Furthermore, the regressions of LCC with MAT did not differ significantly among forests and shrublands in terms of both their slopes and intercepts. However, for the relationships between MAP and LCC, the slopes differed significantly $(P<0.001)$ (Figure 4$)$.

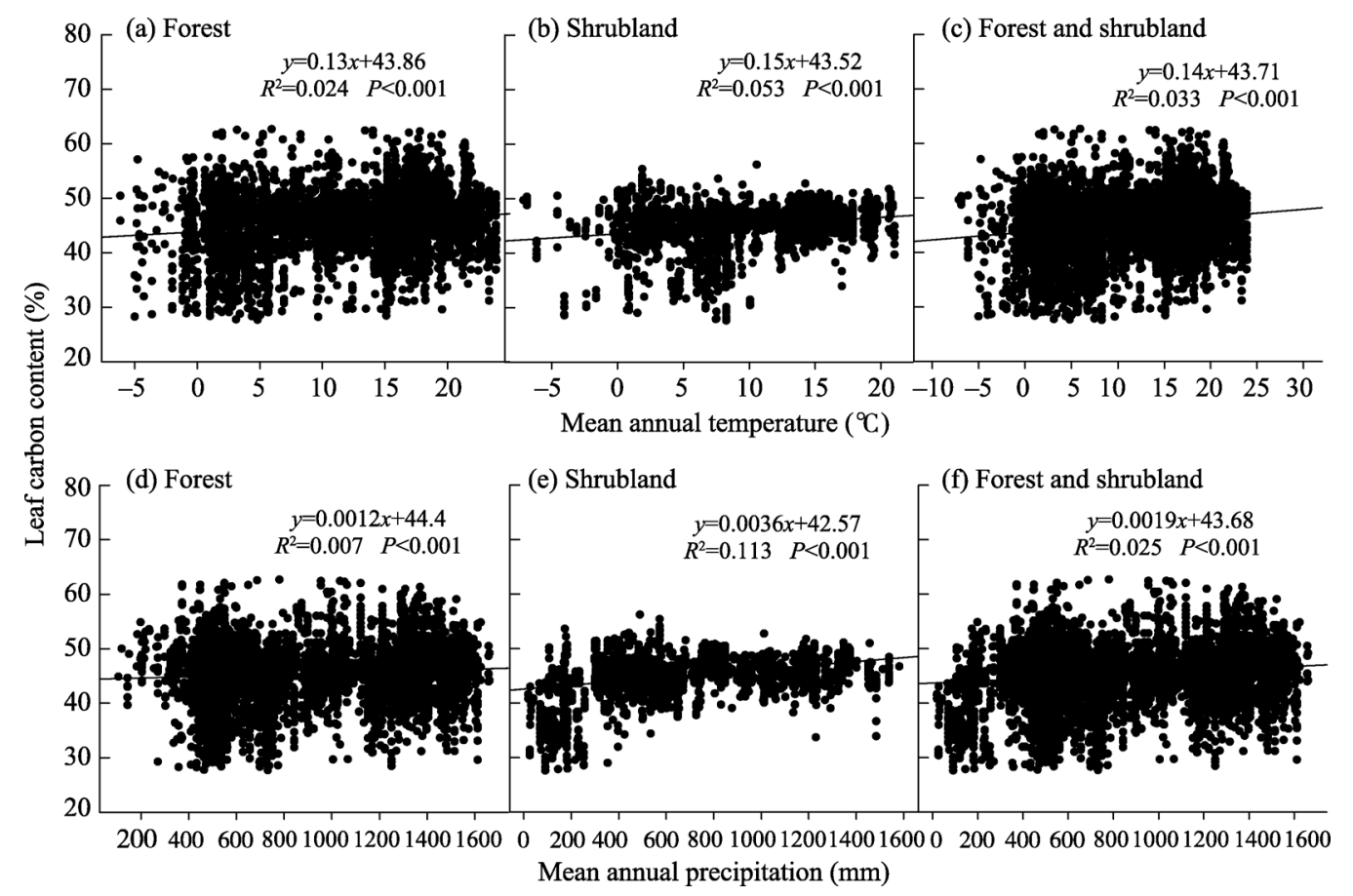

Figure 4 Changes in leaf carbon content (LCC, \%) in the forests and shrublands of China with climate at the plot scale

\subsubsection{Eco-region scale and larger eco-region scale}

At the 24 eco-region (Figure 5) and eight eco-region (Figure 6) scales, LCC was not significantly related to MAT for forests or shrublands. The LCC of shrubs and their combined values with forests increased significantly with MAP at the scale of the 24 eco-regions, while shrub LCC increased significantly with MAP at the larger eco-region scale.

\section{Discussion}

\subsection{Regional differences in LCC}

In this study, forest LCC was $45.51 \%$, which was slightly higher than that of shrublands (44.91\%), and their combined average was $45.30 \%$. As expected, there were obvious regional differences for both forest and shrubland LCC. Forest LCC ranged from $40.18 \%$ to $51.24 \%$ among the regions, whereas shrub LCC ranged from $34.99 \%$ to $50.12 \%$. These different 


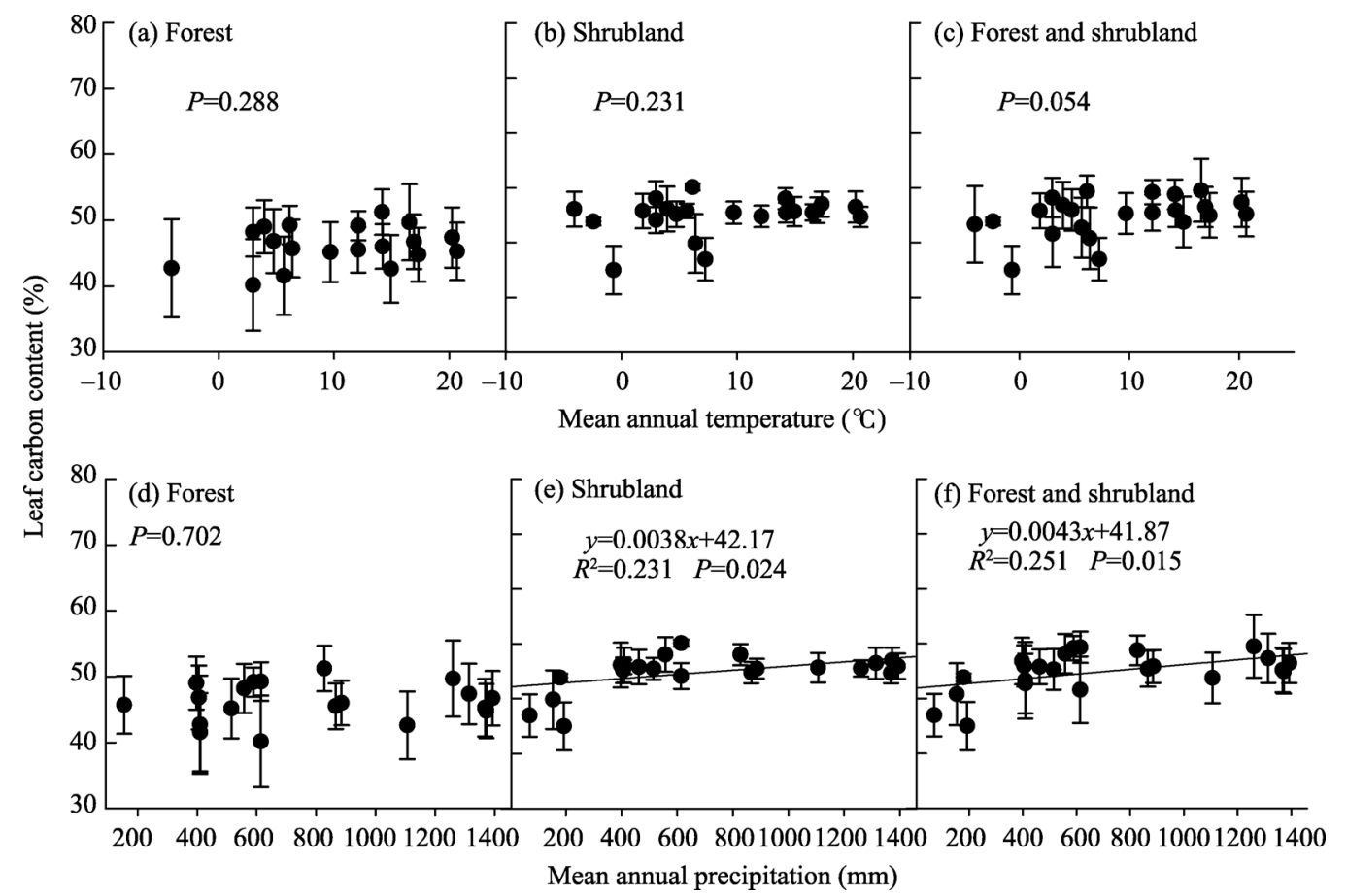

Figure 5 Changes in leaf carbon content (LCC \%) in the forests and shrublands of China with climate at the scale of the 24 eco-regions

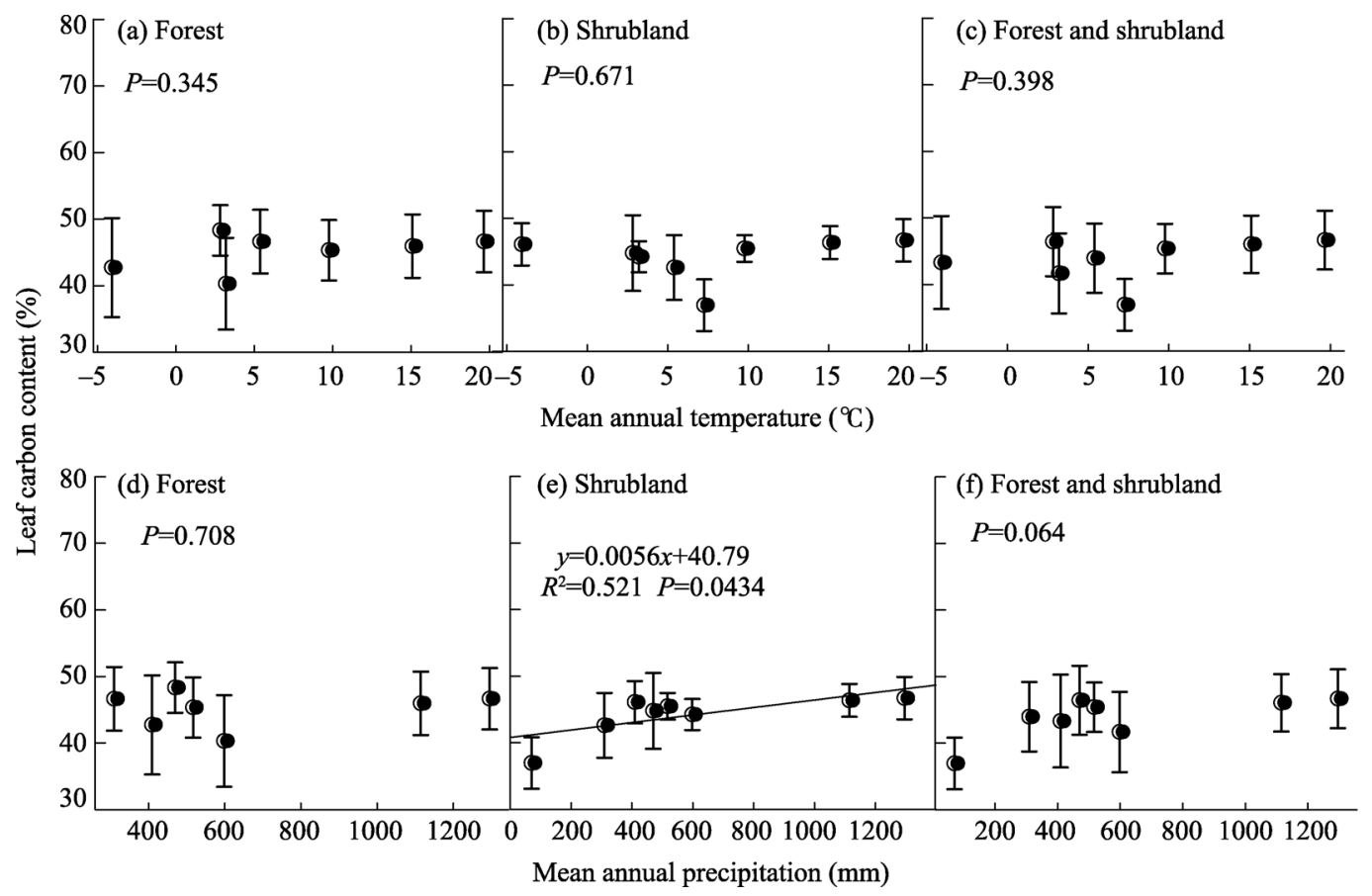

Figure 6 Changes in leaf carbon content (LCC, \%) in the forests and shrublands of China with climate at the scale of the eight eco-regions 
ranges might be attributed to the climatic conditions that limit the distribution of plants and plant physiological characteristics. To adapt to the changing environment, plants adjust their composition, such as the C content, in different organs (Yang, 2001; Yu et al., 2016; Zheng et al., 2007). For example, regions with higher latitude have longer winters that are colder with less rainfall; consequently, the dominant vegetation is boreal forest, the physiological characteristics of which leads to high LCC content. In arid areas, the dominant plants are xerophytes that are adapted to less precipitation, which is an essential characteristic for the survival of plants in these regions, but results in high numbers of organic compounds with lower LCC content (Yang, 2001).

The investigation of 102 dominant plant species by Ren et al. (2012) showed that the LCC along a north-south transect in eastern China ranged from $37.4 \%$ to $64.7 \%$. This finding differed from our results, possibly because we measured mixed leaf samples from a number of dominant species at the community level. Thus, our results might better represent LCC characteristics at a community scale. Zheng et al. (2007) reported global LCC characteristics by deriving LCC data from publicly available datasets; consequently, this previous study combined different sampling methods and different measurement methods. The authors calculated an average of $44.9 \%$ for forest LCC, ranging from $30.5 \%$ to $55.4 \%$, and an average of $47.5 \%$ for shrubland LCC, ranging from $35.5 \%$ to $59.4 \%$. Overall, these reports were consistent with each other.

Han et al. (2009) studied the stoichiometry of 358 plant leaves in Beijing and the surrounding areas. The authors reported an average LCC of $45.1 \%$, based on species level measurements. In addition, Yu et al. (2012) showed that the LCC in the northeast forest region (including Da Hinggan, Xiao Hinggan mountains, Zhangguangcai Mountain, and Changbai Mountain) was $44.5 \%$, using the data from a standard survey. These LCC values were comparable to those obtained in the cold temperate humid areas of the current study, which was $42.7 \%$ for forests, $46.1 \%$ for shrublands, and $43.3 \%$ for the two combined.

Furthermore, the average LCC of 10 shrub species from northern China was 49.4\%, while the average LCC of eight forest species in northern China was 50\% (Ma et al., 2002). These results were similar to those obtained for forest LCC in the current study for warm temperate sub-humid areas (45.2\%) and the shrublands (45.5\%). The average LCC of four dominant tree species in the northwest of Yunnan Province was 51\% (Wang et al., 2012), which corresponded to the forest LCC obtained in the mid subtropical humid area-5 (51.2\%) and its shrubland LCC (48\%) in the current study. In addition, in Gansu Province, the average LCC of 14 shrub species was previously reported as $43 \%$ (Cheng et al., 2008). In this study, the corresponding region was located in the temperate semi-arid area of the Tibetan Plateau-2, in which forest LCC was $49 \%$ and shrubland LCC was $46.1 \%$. Overall, forest and shrubland LCC varied among different regions, which should be incorporated in future studies to obtain more accurate LCC estimates per region.

\subsection{Implication of forest and shrubland LCC in carbon storage assessments}

Leaves are an important component of vegetation $\mathrm{C}$ storage. Vegetation $\mathrm{C}$ storage is generally estimated by multiplying the biomass of different plant components and their corresponding $\mathrm{C}$ content (Yu et al., 2012). However, measuring LCC from different plant species is time-consuming and costly at a large scale. Therefore, many studies prefer to use an empirical average 
(Fang et al., 2001; Navar, 2009; Sykes and Prentice, 1996; Wang et al., 2001). However, LCC is influenced by vegetation type, climate, topography, and other factors. Therefore, understanding large-scale spatial LCC patterns and their variations is essential to develop realistic models.

Our findings showed that LCC exhibited clear regional differences for both forests and shrublands. Therefore, it is not appropriate to use a uniform value of LCC for an entire country, such as China, as this would result in higher uncertainties of $\mathrm{C}$ estimates. Because our large dataset covered all of the many forest and shrubland types in China, we provided a series of LCC standards at different scales for use in future studies (Tables 1 and 2). These findings are expected to help by providing low-cost estimates of $\mathrm{C}$ storage in leaves, which is one of the most important components of $\mathrm{C}$ in terrestrial ecosystems.

Nonetheless, the LCC reported here is not sufficient for evaluating overall vegetation $\mathrm{C}$ storage alone. Some studies have demonstrated that $\mathrm{C}$ content differs among plant organs, and is modified by forest age and phenology. For example, Yang et al. (2014) reported that the $\mathrm{C}$ content of Pinus tabulaeformis plantations was ordered as branch $(46 \%)>$ leaf $(44.8 \%)$ $>$ root $(42.5 \%)$. Furthermore, the $\mathrm{C}$ content of northeast China's forests significantly differ among different plant organs, with leaf $(44.5 \%)>$ branch $(44.2 \%)>$ bark $(44 \%)>\operatorname{trunk}$ (43.5\%) (Yu et al., 2012). Overall, to determine the $\mathrm{C}$ storage in all vegetation types combined, further studies on the $\mathrm{C}$ content of the plant litter, roots, stems, branches, and other plant organs are required at a large scale.

\section{Conclusions}

The average LCC of forests and shrublands was $45.51 \%$ and $44.91 \%$, respectively, and was $45.30 \%$ for the two combined. LCC significantly differed across regions for both forests and shrublands. There were clear spatial patterns in forest and shrubland LCC. Forest LCC decreased with increasing latitude and longitude. In comparison, shrubland LCC decreased with increasing latitude, but increased with increasing longitude. Forest and shrubland LCC were significantly correlated with MAP and MAT, which both gradually increased with increasing MAT and MAP. In conclusion, our study is the first to explore spatial variation in the LCC of forests and shrublands at a national scale. Our findings provide a new reference and standard values for estimating large-scale foliage $\mathrm{C}$.

\section{References}

Bert D, Danjon F, 2006. Carbon concentration variations in the roots, stem and crown of mature Pinus pinaster (Ait.). Forest Ecology \& Management, 222(1-3): 279-295.

Birdsey R A, 1992. Carbon storage and accumulation in United States forest ecosystems. In: General Technical Report. Washington D.C, U.S.: Department of Agriculture, Forest Service, Washington Office.

Chapin F S, Matson P A, Mooney H A, 2002. Principles of Terrestrial Ecosystem Ecology. New York, USA: Springer.

Cheng T R, Feng J, Ma Q Y et al., 2008. Carbon pool and allocation of forest vegetation in Xiaolong Mountains, Gansu Province. Acta Ecologica Sinica, 28(1): 33-44. (in Chinese)

Du H M, Wang C, Gao H Z, 2009. Carbon-sink function of artificial Larix principis-rupprechtii plantation. Chinese Journal of Eco-Agriculture, 17(4): 756-759. (in Chinese)

Ehleringer J R, Field C B, 1993. Scaling Physiological Processes: Leaf to Globe. Vol. 261. San Diego: Academic Press.

Fang J Y, Chen A P, Peng C H et al., 2001. Changes in forest biomass carbon storage in China between 1949 and 1998. Science, 292(5525): 2320-2322. 
Fu B J, Liu G H, Chen L D et al., 2001. Scheme of ecological regionalization in China. Acta Ecologica Sinica, 21(1): 1-6. (in Chinese)

Fu Y, Sun Y J, 2013. A study of the determination of organic carbon of vegetation. World Forestry Research, 26(1): 24-30. (in Chinese)

Han W X, Wu Y, Tang L Y et al., 2009. Leaf carbon, nitrogen and phosphorus stoichiometry across plant species in Beijing and its periphery. Acta Scientiarum Naturalium Universitatis Pekinensis, 45(5): 855-860. (in Chinese)

Houghton R A, Skole D L, Nobre C A et al., 2000. Annual uxes of carbon from deforestation and regrowth in the Brazilian Amazon. Nature, 403(6767): 301-304.

Jagodzinski A M, Jarosiewicz G, Karolewski P et al., 2012. Carbon concentration in the biomass of common species of understory shrubs. Sylwan, 156(9): 650-662.

Liu G H, Fu B J, Fang J Y, 2000. Carbon dynamics of Chinese forests and its contribution to global carbon balance. Acta Ecologica Sinica, 20(5): 733-740. (in Chinese)

Ma Q Y, Chen X L, Wang J et al., 2002. Carbon content rate in constructive species of main forest types in northern China. Journal of Beijing Forestry University, 24(Suppl.1): 96-100. (in Chinese)

Navar J, 2009. Allometric equations for tree species and carbon stocks for forests of northwestern Mexico. Forest Ecology and Management, 257(2): 427-434.

Ren S J, Yu G R, Jiang C M et al., 2012. Stoichiometric characteristics of leaf carbon, nitrogen, and phosphorus of 102 dominant species in forest ecosystems along the North-South Transect of East China. Chinese Journal of Applied Ecology, 23(3): 581-586. (in Chinese)

Shvidenko A Z, Nilsson S, Rojkov V A et al., 1996. Carbon budget of the Russian boreal forests: A systems analysis approach to uncertainty. Apps M J, Price D T. Vol.40. Berlin 33: Springer-Verlag Berlin.

Sykes M T, Prentice I C, 1996. Carbon storage and climate change in Swedish forests: A comparison of static and dynamic modelling approaches. Apps M J, Price D T. Vol. 40. Berlin 33: Springer-Verlag Berlin.

Tolunay D, 2009. Carbon concentrations of tree components, forest floor and understorey in young Pinus sylvestris stands in north-western Turkey. Scandinavian Journal of Forest Research, 24(5): 394-402.

Turner D P, Koerper G J, Harmon M E et al., 1995. A carbon budget for forests of the conterminous United States. Ecological Applications, 5(2): 421-436.

Wang J L, Wang X H, Yue C R et al., 2012. Carbon content rate in dominant species of four forest types in Shangrila, northwest Yunnan province. Ecology and Environmental Sciences, 21(4): 613-619. (in Chinese)

Wang S Q, Yu G R, 2008. Ecological stoichiometry characteristics of ecosystem carbon, nitrogen and phosphorus elements. Acta Ecologica Sinica, 28(8): 3937-3947. (in Chinese)

Wang X K, Feng Z W, Ouyang Z Y, 2001. Vegetation carbon storage and density of forest ecosystems in China. Chinese Journal of Applied Ecology, 12(1): 13-16. (in Chinese)

Xie Z Q, Tang Z Y, Zhao C M et al., 2015. Observation and Investigation for Carbon Sequestration in Shrub Ecosystemss. Beijing: Science Press. (in Chinese)

Yang C H, 2001. Plant Geography. Beijing: Science Press. (in Chinese)

Yang Y J, Chen Y M, Cao Y, 2014. Carbon density and distribution of Pinus tabulaeformis plantation ecosystem in hilly Loess Plateau. Acta Ecologica Sinica, 34(8): 2128-2136. (in Chinese)

Yerena-Yamallel J I, J Jiménez-Pérez, O A Aguirre-Calderón et al., 2011. ConcentraciÓn De Carbono En La Biomasa AÉrea Del Matorral Espinoso Tamaulipeco. Revista Chapingo Serie Ciencias Forestales Y Del Ambiente, XVII(2): 283-291.

Yu G R, Ren W, Chen Z et al., 2016. Construction and progress of Chinese terrestrial ecosystem carbon, nitrogen and water fluxes coordinated observation. Journal of Geograhical Sciences, 26(7): 803-826.

Yu Y, Fan W Y, Li M Z, 2012. Forest carbon rates at different scales in Northeast China forest area. Chinese Journal of Applied Ecology, 23(2): 341-346. (in Chinese)

Zhao M, Yue T, Na Z et al., 2014. Combining LPJ-GUESS and HASM to simulate the spatial distribution of forest vegetation carbon stock in China. Journal of Geographical Sciences, 24(2): 249-268.

Zheng W J, Bao W K, Gu B et al., 2007. Carbon concentration and its characteristics in terrestrial higher plants. Chinese Journal of Ecology, 26(3): 307-313. (in Chinese)

Zhou G Y, Wen D Z, Tang X L et al., 2015. Observation and Investigation for Carbon Sequestration in Forest Ecosystemss. Beijing: Science Press. (in Chinese)

Zhou Y R, Yu Z L, Zhao S D, 2000. Carbon storage and budget of major Chinese forest types. Acta Phytoecologica Sinica, 24(5): 518-522. (in Chinese) 